\title{
¿DON QUIJOTE ASCETA?
}

Los trabajos que hasta ahora han aparecido en ocasión del cuarto centenario de Cervantes hacen esperar quizá cierta conciliación entre quienes declaran a Cervantes exponente de la Contrarreforma y quienes ven en él un erasmista tardío. Del mismo modo cabe esperar que lleguen a verse en armonía el sentido del Quijote y el del Persiles. La más reciente tendencia en la interpretación de Cervantes parece admitir en él un tránsito desde una forma inferior de catolicismo a otra superior: así en William C. Atkinson, ${ }^{1}$ y tambien en Edward Sarmiento, ${ }^{2}$ si bien con argumentos menos convincentes a pesar de cuanto nos dice sobre la evolución de don Quijote de la primera a la segunda parte de la novela. Aquí vuelven a comenzar las dificultades, porque, según observa $M$. Kommerell, ${ }^{3}$ Cervantes evita, con buen acuerdo lógico y artístico, presentar a un loco como sometido a evolución espiritual antes que se recobre de su locura, aunque, por supuesto, podría también admitirse en el monomaníaco una capacidad de evolución moral, como no sea precisamente en la línea de su monomanía. ${ }^{4}$

Sea como fuere, los dos bandos hostiles de críticos sólo han considerado hasta hoy las notas erasmistas y preiluministas del Quijote. No han atendido al problema, no menos importante, de si don Quijote representa el ideal ascético de la Iglesia y la Contrarreforma o está contra él, con el Renacimiento italiano y la tendencia "luterana" de Erasmo y el erasmismo. Convencido por mi parte, con Mack Singleton, de la urgencia de "desechar casi todo lo que se ha dicho sobre... Cervantes y volver a comenzar, rechazando todo lo que no se sostenga después del más severo examen", ${ }^{5}$ voy a reunir todos los pasajes del Quijote que puedan servir de apoyo a la cuestión preliminar de si don Quijote posee o no las cualidades del asceta. Dejo a otros el decidir, finalmente, con materiales tomados de las otras obras de Cervantes, hasta qué punto se identifica éste con el mayor o menor ascetismo de don Quijote. En nuestro limitado intento preferimos atenernos a la opinión de A. A. Parker de que Cervantes siente por don Quijote una compasión mezclada de reproche ${ }^{6}$ y no se identifica simpáticamente con el.

El concepto de un don Quijote ascético se debe principalmente a los ilustradores, pintores, dibujantes y grabadores que explotaron, sin pararse en detalles, el texto

1 The enigma of the Persiles, en BSS, xxiv, 1947, págs. 242-253.

2 Don Quijote and the Holy Images, en TDR, XLrv, 1947, 1, págs. 38-47. Véase también FrIedRICH SchÜRR, Cervantes, Essen, 1947, pág. 159.

3 Humoristische Personifikation im Don Quijote, en DNRund, xlIx, 1939, págs. 209-232.

4 Lucien Libert, La folie de Don Quichotte, Paris, 1909.

5 The date of "La española inglesa", en Hisp, xxx, 1947, pág. 329.

6 Don Quixote and the relativity of truth, en TDR, xurv, 1947, I, págs. 28-37. 
que habla de un don Quijote "seco de carnes, enjuto de rostro $(\mathbf{I}, 1)$, "caballero de la triste figura" (I, 23), "extraña figura" (II, 66), "alto de cuerpo, seco de rostro" (I, 30; II, 14), "las piernas muy largas y flacas" ( $\mathrm{I}, 35$ ), "flaco y amarillo" (I, 52; II, 48), "largo, tendido, flaco, amarillo, estrecho en el vestido" (II, 61), "los ojos hundidos en los últimos camaranchones del celebro" (II, 7), "estirado" (II, 14), "seco, alto, tendido, con las quijadas que por de dentro se besaban la una con la otra" (II, 31), así como de "la longura de su cuello, la flaqueza y amarillez de su rostro" (II, 16), y de su "atenuada flaqueza" (II, 16); en suma, "una fantasma" (II, 16; II, 49).

Así, pues, don Quijote, "seco y amojamado que no parecía sino hecho de carne momia" (II, l), nos parece ciertamente un verdadero asceta como aquel Pedro de Alcántara que Santa Teresa nos muestra "en su flaqueza hecho de raíces de árboles" (Vida, xxvir). Pero estas características de don Quijote, tipo de castellano enjuto, que, obligado a vivir frugalmente por razones económicas (I, 1; II, 13), sufre además penalidades involuntarias, palizas y malos tratos, no tienen nada que ver con el ascetismo, con un retiro voluntario y penitente, un apartamiento al servicio de Dios, del ideal cristiano, o siquiera de un sustitutivo del ascetismo, barnizado de virtud caballeresca; nada tienen que ver con esa "caridad, humildad, fe, obediencia y pobreza... de quien dice uno de sus mayores santos: tened todas cosas como si no las tuviésedes" ( $I, 44)$. Lo mismo puede decirse de la actitud de sosiego ${ }^{7}$ de don Quijote, que parece una madurez ascética de autodominio y como de religioso recogimiento, pero que en el fondo no es sino su natural dignidad castellana, que se deshace y se desmanda a la menor provocación.

A alimentar la ilusión de un Quijote ascético viene también la jactancia con que el propio don Quijote habla de sus heroicos sufrimientos, que él no deja de comparar con los trabajos de los monjes, ermitaños y santos. Cuando el noble Vivaldo (II, 13) le dice: "Paréceme... que vuestra merced ha profesado una de las más estrechas profesiones que hay en la tierra y tengo para mí que aun la de los frailes cartujos no es tan estrecha", don Quijote se apresura a responder: "Tan estrecha bien podía ser, pero tan necesaria en el mundo no estoy en dos dedos de ponello en duda...; los religiosos con toda paz y sosiego piden al cielo el bien de la tierra; pero los soldados y caballeros ponemos en ejecución lo que ellos piden...; no debajo de cubierta sino al cielo abierto... sudando, afanando y trabajando excesivamente; síguese que aquellos que la profesan [la caballería] tienen sin duda mayor trabajo que aquellos que en sosegada paz y reposo están rogando a Dios... No quiero yo decir ni me pasa por pensamiento que es tan buen estado el de caballero andante como el de encerrado religioso; sólo quiero inferir, por lo que yo padezco, que sin duda es más trabajoso" $(\mathrm{r}, 13)$.

En el discurso de las armas y las letras aclara don Quijote: "Veamos si es rico el soldado, y veremos que no hay ninguno más pobre en la misma pobreza... y en la mitad del invierno se suele reparar de las inclemencias del cielo estando en la campaña rasa, con solo el aliento de su boca" (I, 38; ideas similares en II, 17). Don Quijote se atreve hasta a oponer los libros de caballerías, como fuente de virtu-

7 Ejemplos en H. Hatzfeld, Don Quijote als Wortkunswerk, Leipzig, 1927, págs. 11-12. 
des naturales, a las Sagradas Escrituras, como fuente de virtudes cristianas, en la plática con el canónigo de Toledo, quien amonesta a don Quijote: "Lea en la sacra Escritura... de la cual saldrá enamorado de la virtud, enseñado de la bondad, mejorado en las costumbres, valiente sin temeridad, osado sin cobardía, y todo esto para honra de Dios" ( $\mathrm{I}, 49)$. Don Quijote responde: "Lea estos libros [de caballerías] y verá cómo... le mejoran la condición... De mí sé decir... que soy valiente, comedido, liberal, bien criado, generoso, cortés, atrevido, blando, paciente, sufridor de trabajos" $(1,50)$.

Vemos, pues, que don Quijote está convencido de que posee, ni más ni menos que un santo, "la virtud en eminente grado" (II, 2). En una de sus famosas discusiones con Sancho, trata de llevar las cosas hasta el punto en que las virtudes cristianas, oponiéndose a los pecados capitales, pudieran ser acrecentadas por las asperezas de la vida militar, pero Sancho lo deja algo corrido cuando le pregunta si hay en tal caso más caballeros que monjes en el cielo: "-Quiero decir, Sancho, que... los cristianos catolicos más habemos de atender a la gloria de los siglos venideros... que a la vanidad de la fama; así... hemos de matar... a la ira..., a la gula y al sueño en el poco comer... y en el mucho velar..., a la lujuria y lascivia en la lealtad... y a la pereza con andar por todas partes del mundo buscando las ocasiones que puedan hacer y hagan, sobre cristianos, famosos caballeros... No todos podemos ser frailes, ...religión es la caballería, caballeros santos hay en la gloria. - Sí, respondió Sancho, pero yo he oído decir que hay más frailes en el cielo que caballeros... - Eso es, respondió don Quijote, porque es más el número de los religiosos que el de los caballeros. - Muchos son los andantes, dijo Sancho. - Muchos, respondió don Quijote, pero pocos los que merecen nombre de caballeros" (II, 8).

El caballero a carta cabal, como don Quijote repite a don Diego de Miranda, tiene todas las dotes ascéticas del santo cristiano y, por añadidura, dotes caballerescas y seculares que lo complementan: "Dejando aparte que... ha de estar adornado de todas virtudes teologales y cardinales..., digo que ha de saber nadar..., herrar un caballo..., ha de ser casto en los pensamientos, sufrido en los trabajos, caritativo con los menesterosos" (II, 18).

Al acercarse, más adelante, a la cabaña de un ermitaño en el bosque, don Quijote tiene en menos el ascetismo de los cenobitas modernos comparándolos con los de la antiguiedad y viéndolos como por debajo del ideal que él se precia de mantener: "Pocos ermitaños están sin [gallinas]..., porque no son los que ahora se usan como aquellos de los desiertos de Egipto que se vestían de hojas de palma, y comían raíces de la tierra..., quiero decir que al rigor y estrecheza de entonces no llegan las penitencias de los de ahora" (II, 24). Porque don Quijote se declara amigo decidido de la pobreza: "Holgárame de quedarme pobre y sin blanca" (Ir, 28). Esta nota crítica y radical en la jactancia ascética de don Quijote es extremadamente notable y llamativa: "Se nos manda que... amemos a los que nos aborrecen: mandamiento que aunque parece algo dificultoso de cumplir, no lo es sino para aquellos que tienen menos de Dios que del mundo y más de carne que de espíritu" (II, 27).

Pero él, como explica al capellán de los duques, siendo perfecto y pobre, se acerca al cielo por "las asperezas por donde los buenos suben al asiento de la in- 
mortalidad" (II, 32) con mayor confianza que los monjes y sacerdotes: "Unos van por el ancho campo... de la verdadera religión; pero yo... voy por la angosta senda de la caballería andante, por cuyo ejercicio desprecio la hacienda" (II, 32). El caballero secular compite con la religión hasta auxiliando a los difuntos: "La caballería andante..., cuyo ejercicio aun hasta hacer bien a las ánimas del purgatorio se extiende" (II, 48). Sólo una vez se muestra don Quijote más modesto, cuando contempla los retablos con los cuatro santos: "Ellos conquistaron el cielo a fuerza de brazos... y yo hasta ahora no sé lo que conquisto" (II, 58). Pero esto está muy lejos de ser una conversión de su parte, porque aún trata a su vez de convertir a Roque Guinart en caballero andante como adecuada penitencia por su pecaminosa vida y como atajo al cielo: "Si vuesa merced quiere ahorrar camino y ponerse con facilidad en el de su salvación, véngase conmigo, que yo le enseñaré a ser caballero andante, donde se pasan tantos trabajos y desventuras que, tomándolas por penitencia, en dos paletas le pondrán en el cielo" (II, 60). Pero Roque Guinart se ríe de don Quijote y de sus "penitencias caballerescas", como lo hace también Sancho cuando le dice muy por lo claro: "No soy religioso para que desde la mitad de mi sueño me levante y me discipline" ( $\mathrm{n}, 68)$.

Contrastando con esta engañosa apariencia de un don Quijote ascético que no aparece sino en sus propias palabras, hay un don Quijote más objetivamente reflejado en las críticas del autor, ya directamente, ya a través de los otros personajes de la novela. Este don Quijote no tiene ni siquiera los requisitos elementales del asceta. No hace nada para reprimir sus más peligrosas inclinaciones, su irascibilidad, su orgullo, su disgusto de las mortificaciones, abstinencias y sufrimientos, su concupiscencia siempre al acecho, su curiosidad egocéntrica por el mundo y su gran temor de perder la vida.

La irascibilidad de don Quijote, "mohino y colérico" (I, 29), prácticamente no reconoce límites y no puede excusarse por sus "primeros movimientos, que no son en manos de los hombres" ( $I, 30)$, ni por su "justa cólera" ( $I, 3)$, o "justa ira" (I, 16), o "justo enojo" (II, 32), ni siquiera por su temperamento castellano: "La gente manchega es tan colérica como honrada" (II, 10). Apenas hay ocasión en que, "enojado", no le suceda que primero "vino a correrse" ( $x, 2)$, y después se "acrecentaba en él el enojo" ( $1,2,30,37,48)$. Se queda "muy despechado" (II, 46), "mohinísimo" (I, 22), "corridísimo" ( $\mathrm{I}, 31$ ), o "encolerizado" ( $\mathrm{I}, 19)$, "encendido en cólera" (I, 4, 7, 17, 21, 22; II, 11, 17, 28), "encendido y colérico" (II, 58), "lleno de ira y de despecho" (II, 59), "con furia y enojo" (I, 4), "rabia" (I, 9; II, 31), "furiosa indignación" ( 1,14$)$, "rencor" ( $r, 30)$, "ira" ( 1,46$)$, "furibundos ademanes" (r, 46); "furia" (I, 9), "nunca vista furia" (II, 26), "desatinada cólera" (II, 26), "airado y alborotado rostro" (II, 31), "con gran furia y muestras de enojo" (II, 58).

Sus "amenazas" (II, 14) están llenas de ira y violencia: "no dejar persona viva" $(\mathrm{I}, 3)$, "aniquilar" $(\mathrm{I}, 4)$, "pelar y quitar las barbas" ( $\mathrm{I}, 7)$, "hacer un estrago" (I, 37), "arrancar el alma" (II, 35), "sacar el alma a puntillazos" (II, 63). A veces llega a golpear a los otros, particularmente, claro está, a Sancho: "Se corrió y enojó en tanta manera que alzó el lanzón y le asestó dos palos" ( 1,20$)$, "no lo pudo sufrir y... 
le dió dos palos" ( $\mathrm{r}, 30$ ), o derriba a las gentes por tierra: "Con mucha cólera arrojble [a Cardenio] comro tenía de costumbre" (I, 24); y aun trata de estrangular a los que tiene cerca: "puesta la cólera en su punto asib al cuadrillero... de la garganta" ( $I, 45)$, o les da en la cara con lo que tiene a su alcance: "arrebató de un pan... y dió con él al cabrero con tanta furia que le remachó las narices" (I, 52).

El irascible caballero ni siquiera piensa en refrenar la lengua, a pesar de que sabe teóricamente que "cuando la cólera sale de madre, no tiene la lengua padre, ayo ni freno que la corrija" (II, 27). Así, con una increíble falta de mesura aplica denuestos a todo el mundo (particularmente a Sancho): "traidor" (I, 3; II, 17), "glotón" (II, 20, 66), "cobarde" (I, 4, 8; II, 41), "follón" (I, 3, 30, 35; II, 28), "faquín" (I, 30), "canalla" ( $(1,3,4$; II, 29, 58), "sandio" (I, 17) , "belitre" (I, 30), "malandrín" (I, 18, 35; II, 28), "gañán" (I, 90), "bellaco" (I, 22, 24, 52; II, 17), "bellacuelo" (I, 37), "don hijo de la puta" (I, 22), "majadero" (I, 30), "bergante". (II, 17), "villano" (I, 31, 46; II, 35), "ladrón" (I, 3.5, 37, 45; II, 41), "tonto" (II, 34, 58), "loco" (I, 37), "mentecato" (II, 37; II, 9), "bobo" (II, 6), "maldito" (II, 9, 19, 34), "hereje" (II, 9), "truhán" (I, 31), "animal" (II, 19, 41), "asno" (II, 28), "bestia" (II, 28, 62), "harto de ajos" (II, 35), "vestiglo" (II, 28), "gente soez" (I, 45), "endiablada" ( $\mathrm{I}, 8)$, "infame" ( $\mathrm{I}, 45)$ ), "viles criaturas" ( $\mathrm{I}, 8)$.

A pesar de cuanto don Quijote dice, no hay en él intención alguna de servir verdaderamente a los demás, de ser humilde, de renunciar al egoísmo y al orgullo. Si los sufrimientos y las aventuras lo atraen, no es por renunciamiento, sino por propia satisfacción, por ganar fama y honra, gloria y vanagloria: "para que cobrase eterno nombre y fama" (I, 1), "sólo por alcanzar gloriosa fama" (II, 17), o "gloria" (II, 41), "para memoria en lo futuro" (I, 2), "perpetuo nombre y fama en todo lo descubierto de la tierra" (I, 25), "andar en boca de la fama" (r, 37), "hacerse famoso y conocido" ( $\mathrm{I}, 38)$, "hacer obras y hazañas para que otros las cuenten y las escriban" (II, 37), "andar por las lenguas de las gentes impreso y en estampa" (II, 3). Se llama a sí mismo "valeroso" ( $1,4,10)$, "valiente, nombrado" (I, 4), "intrépido y fuerte" (II, 34), "llevado de la honra" (I, 38), "si no tan bravo como los pasados caballeros, a lo menos no inferior" (II, 1), "con ánimo de tomarme con el mismo Satanás" (II, 17). Habla de sus "obras escritas en el libro de la fama" (I, 18), "valerosas, muchas y cristianas hazañas" (II, 16). De sí mismo dice: "yo sé quién soy" $(I, 5)$, "agradezco mucho la buena opinión que de mí se tiene" ( $I, 37)$, "yo valgo por ciento" ( $\mathrm{I}, 15)$, "mi persona es tal que si yo no la alabo es por lo que suele decirse que la alabanza propia envilece" ( $\mathrm{I}, 15)$, "tal debe ser la fuerza del brazo que tal mano tiene" ( $\mathrm{r}, 43$ ), "no habrá imposible a quien yo no acabe" (II, 23). Alaba "la fuerza de mi incansable brazo" (I, 46), "el valor de mi brazo" (II, 29, 31 et passim), "la intrépida resolución de mi animoso espíritu" (II, 36). Ordena a Sancho "que jamás has de decir a nadie que yo... me aparté de este peligro por miedo" (I, 23). Está orgulloso de su fama imaginaria: "Hasta los muchachos... sin nunca haberme visto me conocen" (II, 61), y "alegre sobre manera de verse tratar a lo señor" (II, 63). Orgulloso de su familia: "Gutierre Quijada de cuya alcurnia yo desciendo" ( 1,49 ); de su viril presencia: "Bien veo que no soy hermoso, pero también conozco que no soy disforme" (nI, 58), y particularmente de su honor. De ahí 
que sean un acto de orgullo sus más dramáticas palabras, cuando lo vencen en la playa de Barcelona: "Quítame la vida pues que me has quitado la honra" (II, 64); aun al decir que "esta afrenta es pena de mi pecado" (II, 68) nos demuestra que el orgullo del vencido don Quijote prevalece todavía en su alma. Teme "al profundo abismo del olvido" ( $\mathrm{n}, 32$ ). Rechaza toda culpa o responsabilidad: "toda [desgracia] la atribuía a la falta de su caballo" ( $1,4,5)$, "al poderoso grandor del caballo del de la Blanca Luna no podía resistir la flaqueza de Rocinante" (II, 66); en todas las otras ocasiones atribuye sus propias fallas a los manejos de los encantadores. Hace gala de un "ademán arrogante" ( $\mathrm{I}, 4,43$; II, 58), "impertinente" (II, 11), "ufano y vanaglorioso" (II, 15; cf. "ufanidad", II, 16).

Al irascible, egocéntrico y orgulloso don Quijote no le interesan ayunos y abstinencias. Aunque no tan insistentemente como Sancho, habla a cada instante de comida, no obstante sus ascéticos discursos. Veamos algunas expresiones "no censuradas" del hombre que no rechaza "algún palomino de añadidura" ( 1,1$)$, ni "un par de pichones" (II, 3): "Cualquiera [cosa] yantaría yo, porque, a lo que entiendo, me haría mucho al caso... que el trabajo y peso de las armas no se puede llevar sin el gobierno de las tripas" ( $\mathrm{I}, 2)$, "Que le diesen de comer y le dejasen dormir, que era lo que más le importaba" $(1,5)$, "Por ahora tráiganme de yantar, que sé que más me hará al caso" ( $\mathrm{I}, 7)$, "Mira si traes algo en esas alforjas que comamos" ( $I, 10)$, "No digo yo que sea forzoso no comer otra cosa sino esas frutas" ( $\mathrm{x}, 10)$, "Tomara yo más aína un cuartel de pan o una hogaza y dos cabezas de sardinas arenques que cuantas hierbas describe Dioscórides" ( 1,18$)$, "Yo me desmayo de ayuno" (II, 68). Haciendo de penitente dice con tristeza: "Aunque tuviera, no comiera otra cosa que las yerbas" (I, 25): casi parece dar a entender implícitamente un "bocado que bien me sepa" (II, 2). En fin, aconsejando a Sancho: "Siempre favorece el cielo a los buenos; y vámonos a comer" (II, 43).

Come, y bien a gusto, con los pastores, con don Diego de Miranda, en las bodas de Camacho, con el duque y la duquesa, con las hermosas pastoras (II, 58), con don Antonio Moreno. Veamos, en primer lugar, algunos ejemplos de sus nada ascéticas actitudes en lo que toca al comer: "Con mucho donaire y gala embaulaba tasajos como el puño" (I, 11), "hubo bien satisfecho su estómago" (II, 11), "dieron [Sancho y don Quijote] saco a las alforjas" ( $\mathrm{x}, 15)$, "el amo [don Quijote] con gana de comer" ( $\mathrm{I}, 19)$. Don Quijote se preocupa de tener "proveídas las alforjas de cosas tocantes a la bucólica" (Ir, 7), "pidió que le diesen algo de comer, que traía grandísima hambre" (II, 23). En segundo lugar, tenemos la serie de experiencias del caballero en diferentes mesas. En el castillo de los duques goza sentado a la mesa "en acabando de comer" (II, 23), "y en cenando" ( $I$ I, 44), "estando à la mesa con los-duques" (II, 52). Un vivir tan regalado, en suma, que hasta le entran escrúpulos. "La vida que en aquel castillo tenía era contra toda la orden de caballería que profesaba" (II, 52); "se imaginaba ser grande la falta que su persona hacía en dejarse estar encerrado y perezoso entre los infinitos regalos y deleites... y parecíale que había de dar cuenta... al cielo de aquella ociosidad" (II, 57). Pero sigue echándola de menos y como saboreándola cuando deja el castillo: "Digo esto, Sancho... que el regalo, la abundancia..., aquellos banquetes sazonados y... aquellas bebidas... no 
lo gozaba con la libertad que lo gozara si fueran míos" (II, 58). El mismo día en que hace voto de volver a las asperezas de la vida rústica, las hermosas pastoras de las redes lo invitan a su fiesta, y él vuelve a sentarse a "mesas puestas, ricas, abundantes y limpias" (II, 58). A poco de este agasajo, cuando lo atropellan los toros y culpa a Sancho: "Yo, Sancho, nací para vivir muriendo, y tú para morir comiendo... don Quijote comió algo" (II, 59); esa misma noche don Quijote se detiene en una venta: "Llegóse... la hora del cenar, recogióse a su estancia don Quijote, trujo el huésped la olla" (II, 59), pero don Quijote, "delicado" (II, 59), prefiere cenar con los ricos caballeros don Jerónimo y don Juan: "Cenó con ellos: quedóse Sancho con la olla" (II, 59). También en Barcelona, en la casa de don Antonio Moreno, "cenóse espléndidamente" (II, 62), lo que contrasta con la indiferencia de don Quijote después de su última derrota, cuando no le importa que cenaran "tarde y mal" (Ir, 67). En su segunda visita al castillo cena aún mejor: "comió con los duques" (II, 70). Continuando su regreso, no rehusa "el repuesto de Sancho" (II, 71) y parando en un mesón come con Álvaro Tarfe: "Llegose... la hora de comer, comiernn juntos don Quijote y don Álvaro" (II, 72).

De penitencias y mortificaciones don Quijote escoge, contra las prácticas del ascetismo, la "más fácil" (r, 25), esperando que "presto se acabará mi pena" ( $\mathrm{r}, 25)$. Se refiere aquí a su penitencia en la sierra, que él llama con exageración "un infierno" ( $\mathrm{r}, 25)$, pero que otros califican irónicamente de "extraordinaria" ( $\mathrm{r}, 31)$ y "asperísima" (I, 28) o, sin ironía, de "inútil" (I, 26) y "vana" (1, 27).

Disgustándole a don Quijote las mortificaciones, pone su ilusión suprema en una sobrehumana "honestidad" (II, 31) y castidad: "castos oídos" (II, 48), "mis castas orejas" ( $\mathrm{r}, 28)$. No solamente se entrega a un amor platónico (I, 25; II, 32), que excluye el matrimonio: "Yo no soy casado, ni... me ha venido en el pensamiento serlo" (II, 22), "no es posible... ni por pienso el casarme aunque fuese con el ave Fénix" (I, 30); elige como símbolo a Dulcinea, a quien, segunda Beatriz, invoca casi como a una santa (I, 8, 43; Ir, 56, etc.). Dulcinea es símbolo de la "idea de todo lo provechoso, honesto y deleitable" ( 1,43$)$. Tiene, sin duda, algo de absoluto, algo de Dios mismo, a quien se entrega uno sin pensar en recompensas: "Servilla sólo por ser ella quien es, sin esperar otro premio." A lo que Sancho comenta: "Con esa manera de amor he oído yo predicar que se ha de amar a Nuestro. Señor por sí solo, sin que nos mueva esperanza de gloria o temor de pena" $(1,31)$.

A pesar de tan platónico discurrir, don Quijote está muy lejos de la continencia, la mortificación o la represión. En su vida consciente y vigilada, sigue, por supuesto, el principio de que "de las cosas obscenas y torpes los pensamientos se han de apartar, cuanto más los ojos" (Ir, 59). Pero cuando Maritornes trata de hacer una amorosa visita al lecho del arriero y se detiene por equivocación junto al de don Quijote, éste "la asió fuertemente de una muñeca, y tirándola hacia sí... la hizo sentar sobre la cama; tentóle luego la camisa... y teniéndola bien asida, con voz amorosa... le comenzó a decir: Quisiera hallarme en términos de pagar tamaña merced... pero yago $\tan$ molido y quebrantado que aunque de mi voluntad quisiera satisfacer a la 
vuestra, fuera imposible...; si esto no hubiera de por medio no fuera yo tan sandio... que dejara pasar en blanco la venturosa ocasión" (I, 16). Al salir de la venta, creyendo que la visitante nocturna había sido la princesa, hija del castellano ventero, "no quitaba los ojos della" (I, 16). Cuando el jocoso barbero inventa para el pobre caballero enjaulado un oráculo que habla de "cuando el furibundo león manchego con la blanca paloma tolosina yacieren en uno", don Quijote se olvida al momento de sus "principios" y suplica jubilosamente: "Pidas... al sabio encantador... que no me deje perecer en esta prisión...; hasta ver cumplidas tan alegres... promesas... tendre... no por duro campo de batalla este lecho..., sino por cama blanda y tálamo dichoso" (I, 46). También la duquesa agita el ánimo de don Quijote haciéndole burlas con términos amorosos: "La blanca paloma se verá... en brazos de su querido arrullador" (II, 42). El mismo don Quijote revela su extremada debilidad a las tentaciones cuando la duquesa finge poner cuatro hermosas jóvenes a su servicio: "Le han de servir cuatro doncellas... hermosas como unas flores. - Para mí, respondió don Quijote, no serán ellas flores, sino como espinas que me puncen el alma; déjeme... que yo ponga una muralla en medio de mis deseos y de mi honestidad. - Tanto se temía de encontrar ocasiones que le moviesen o forzasen a perder el honesto decoro" (II, 44).

Cuando Altisidora canta por broma bajo la ventana de su habitación, don Quijote no puede dormir "envuelto en los pensamientos... de la enamorada doncella... Acostóse con ellos y, como si fueran pulgas, no le dejaron dormir... un punto" (II, 46); "estando despierto y desvelado pensando... en el perseguimiento de Altisidora... imaginó que la enamorada doncella venía para sobresaltar su honestidad..." (II, 48). Al entrar en su cuarto la vieja doña Rodríguez, le vienen muchos "edificantes pensamientos": "le sobrevinieron mil pensamientos... y decíase: - ¿Quién sabe si el diablo... querrá engañarme ahora con una dueña... y quién sabe si esta soledad, esta ocasión y este silencio despertará mis deseos...; pero yo no debo de estar en mi juicio... que no es posible que una dueña toquiblanca... pueda mover ni levantar pensamiento lascivo...? ¿Por ventura hay dueña en la tierra que tenga buenas carnes?... Afuera pues... caterva dueñesca inútil para ningún humano regalo" (II, 48). Atraído por las indecorosas ternuras de Altisidora y huyendo al mismo tiempo de ellas, don Quijote siente que no es invulnerable. Sólo cuando sale del castillo "libre y desembarazado de los requiebros de Altisidora, le pareció... que los espíritus se le renovaban..." (II, 58), pero dice a Sancho: "Declaró Altisidora sus deseos, que engendraron en mi pecho antes confusión que lástima" (II, 58). Días después de la separación de Altisidora, cuando Sancho ha merendado con Tosilos, lacayo y mensajero del duque, cerca de Barcelona, don Quijote interroga a Sancho:: “'Preguntaste a ese Tosilos..., qué ha hecho Dios de Altisidora, si ha llorado mi ausencia, o si ha dejado ya en las manos del olvido los enamorados pensamientos que en mi presencia la fatigaban?... Quísome bien, al parecer, Altisidora... lloró en mi partida, maldíjome..., quejóse a despecho de la vergüenza públicamente: señales todas de que me adoraba" (II, 67). La visita matutina de Altisidora a don Quijote, la segunda vez que éste se aloja en el castillo de los duques, lo pone "turbado y confuso" (II, 70).

Altisidora debe haber hecho impresión en la sensualidad de don Quijote, como 
puede verse cuando narra los sucesos de la cueva de Montesinos. Ahí la encantada Dulcinea trata de sacarle algún dinero dejándole en prenda un "faldellín de cotonía nuevo" (Ir, 23). Probablemente esto es lo que mueve a Altisidora a quejarse con insolencia de que don Quijote le ha robado las ligas (II, 41). Con la cabeza llena de imágenes sensuales, don Quijote no da con el tono justo para saludar a la graciosa y elegante pastora de las redes: "No debió de quedar más suspenso... Anteón [es decir, Acteón] cuando vió al improviso bañarse... a Diana, como yo... en ver vuestra belleza" (II, 58). Además, uno de sus sueños de caballero andante es que se llegue a decir de él "¿Qué doncella no se le aficionó y se le entregó rendida a todo su talante y voluntad?" ( $\mathrm{I}, 45)$. Receloso de que el supuesto escritor de sus hazañas pudiera también leerle pensamientos tales como "ha de tener otro [lunar] Dulcinea en la tabla del muslo" (II, 10), y no limitarse a transcribir sus hechos, "temíase no hubiese tratado sus amores con alguna indecencia" (II, 3). Pensando en otras mujeres "deseaba que hubiese declarado su fidelidad [a Dulcinea] y... el decoro que siempre la había guardado..., teniendo a raya los ímpetus de los naturales movimientos" (II, 3). Devanando pensamientos eróticos, no escandalizan a don Quijote las impertinentes preguntas de los caballeros don Jerónimo y don Juan sobre "si [Dulcinea] estaba parida o preñada... o en... su entereza", y contesta con desenfado: "Dulcinea se está entera" (II, 59). Sin embargo, en sus sueños y pensamientos no se le aparece el ángel inaccesible de Dulcinea, sino que "le parecía... ver brincar y subir sobre su pollina a la convertida en labradora Dulcinea" (II, 60). El sueño de don Quijote sobre una escena que alguna vez fué realidad, deja ver una faceta muy especial de la verdad del problema de Dulcinea. La soñada y encantada deja de ser la ideal Beatriz para hacerse cada vez más corpórea. A don Quijote vuelven a traicionarle sus pensamientos cuando las señoras de Barcelona, en la fiesta de don Antonio, fingen coquetear con él: "Fugite, partes adversae: dejadme en mi sosiego, pensamientos mal venidos; allá os avenid señoras, con vuestros deseos" (II, 62). Es siempre el mismo desasosiego en que "como moscas a la miel le acudían y picaban pensamientos" (II, 67), preocupación central del aspirante a asceta, correspondiente a la comparación que hace Santa Teresa de los pensamientos de cualquier clase, incluso los más inocentes, con las inquietas manecillas de un reloj que impiden todo recogimiento. $\mathrm{Al}$ planear un cambio de vida, del estilo caballeresco al pastoril, al asceta en teoría se le escapa que está usando el apartamiento, combinado con esta moda, como preparativo para la delectatio morosa de nuevos pensamientos: "tenía pensado... entretenerse en la soledad de los campos, donde a rienda suelta podía dar vado a sus amorosos pensamientos" (II, 73).

La fantasía de este predicador ascético que es don Quijote se despierta a cada momento, porque ni siquiera intenta cerrar a la tentación el camino de los sentidos. Está siempre alerta, no en espera de peligrosas aventuras, como quisiera hacer creer, "vivir contino alerta siendo a todas horas centinela de mí mismo" (II, 60), sino pendiente de cualquier incidente que suceda a su alrededor, de todo lo que Pascal llamaría divertissement. Por eso, vive devorado de curiosidad por niñerías y nonadas. Cuando descubre la maleta de Cardenio, "con gran deseo quedó el Caballero de la Triste Figura de saber quién fuese el dueño de la maleta" (I, 23), y divisando desde 
lejos a Cardenio, "quedó con más deseo de saber quién era el desdichado loco" (i, 23). Insiste en que un cabrero le muestre el camino que lo lleve a Cardenio, después que éste ha escapado sin contar la mitad de la historia, "porque quedaba con grandísimo deseo de saber el fin" ( $I, 24)$. No menos ansioso se muestra don Quijote por saber la historia de Eugenio: "Me falta dar al alma su refacción... escuchando el cuento deste buen hombre" (I, 50). Cuando le dicen que han escrito un libro sobre él, don Quijote se excita: "No comeré bocado... hasta ser informado de todo" (II, 2). "Como él era algo curioso y siempre le fatigaban deseos de saber cosas nuevas" (II, 24), se comporta casi puerilmente con el conductor de las armas. A fin de oír la historia de éstas, a las cuales alude el conductor con cierto misterio, don Quijote hasta se aviene a hacer obra escuderil y lo ayuda en el establo para que tarde menos en comenzar a narrarla: "No se le cocía el pan a don Quijote... hasta oír y saber las maravillas prometidas del hombre conductor de las armas... Díjole que en todo caso le dijese luego lo que había de decir... - ...y os ayudaré en todo...- ...y así lo hizo" (II, 25). Cuando la duquesa finge tener escrúpulos en abrir una carta dirigida a Sancho por su mujer Teresa Panza, don Quijote siente tal curiosidad de enterarse de su contenido que la abre bajo pretexto de hacer un favor a la duquesa: "La duquesa pidió parecer a don Quijote si sería bien abrir la carta que venía para el gobernador... don Quijote dijo que el la abriría por darle gusto y así lo hizo" (II, 52). Aun cuando la malvada dueña doña Rodríguez murmura de su adorada duquesa, don Quijote no puede resistir la tentación de participar del chisme por pura curiosidad: “'Santa María!... ¡Y es posible que mi señora la duquesa tenga tales desaguaderos!" (II, 48); en esta ocasión por culpa de su curiosidad recibe una recia paliza. En la imprenta de Barcelona don Quijote pregunta por las palabras italianas sólo por gusto de conversar de estas pequeñeces: "Digo esto... por curiosidad no más, ¿ha hallado en su escritura alguna vez nombrar piñata?" (II, 62).

Don Quijote está entregado al mundo, le es imposible apartarse de él, y ha de pagar esta falla con su mayor descalabro moral como caballero. El que se dice intrépido defensor de viudas y huérfanos anda siempre quejándose de sufrimientos corporales, vive en continua ansiedad por su vida. Esto ocurre siempre que el gusto por las aventuras, la ira o la curiosidad no contrapesan esa falla fundamental del "héroe". Don Quijote, apaleado por los mercaderes de Toledo, "tristemente se quejaba" $(\mathrm{r}, 5)$. Lastimado, aunque no muy seriamente, por los molinos de viento, advierte: "si no me quejo del dolor es porque..." ( $(1,8)$, pero lastimado más dolorosamente por "la pesadumbre de aquel desaforado golpe [del vizcaíno] dió una gran voz" (I, 8) y dijo gimiendo a Sancho: "Yo te voto a Dios que me va doliendo mucho la oreja" (1, 10). Molido a golpes por los arrieros yangüeses (1, 15), su pobre justificación es que "espaldas... criadas entre sinabafas y holandas claro está que sentirán más el dolor" (I, 15). Golpeado en la venta, se lamenta "con el mismo tono de voz" $(\mathbf{I}, 17)$ y "estaba con las manos en la cabeza quejándose del dolor del candilazo" (I, 17). Cuando en el castillo de los duques le salta un gato al rostro y lo araña, "por dolor... don Quijote comenzó a dar los mayores gritos que pudo" (II, 46).

La medrosidad de don Quijote no es menor que su incapacidad para sufrir 
dolores. Cuando la procesión funeral de encamisados y hachas encendidas aparece en el horizonte, "los cabellos de la cabeza se le erizaron..., bien bastaba para poner miedo en el corazón [de don Quijote]" (I, 19). En la aventura de los batanes, se da cuenta de que Sancho advierte su temor y dice: "Las tinieblas desta noche, su extraño silencio... son bastantes a infundir miedo, temor y espanto en el pecho del mismo Marte" (I, 20). Cuando ve las grandes narices postizas del fingido escudero Tomé Cecial, no puede menos de sentir miedo: "Las desaforadas narices de aquel escudero... son tales... que a no ser yo quien soy también me asombraran" (II, 14). Gran fortuna es la suya cuando, frente a los leones, puede desafiar a los que lo rodean: "si soy hombre que se espanta" (II, 17), y jurar, cuando el sucro de los requesones le corre por el rostro: "si es que sudo, en verdad que no es de micdo" (II, 17). Más que dichoso al ver que los leones no hacen caso de sus bravatas, el subconsciente aún traiciona el miedo que don Quijote siente, cuando dice: "Mejor suena en las orejas...: el tal caballero es temerario y atrevido, que no: el tal caballero es tímido y cobarde" (Ir, 17).

Las aventuras preparadas por los duques asustan terriblemente a don Quijote. En la cacería se oye "un són tan confuso y tan horrendo que fué menester que don Quijote se valiese de todo su corazón para sufrirlo" (II, 34); entre las figuras que rodean al carro triunfal está "la figura de la muerte, descarnada y fea, de que don Quijote recibió pesadumbre" (Ir, 35). Cuando oye el "ronco tambor" que anuncia a los enviados de la condesa Trifaldi, "don Quijote no cabía en su asiento de puro alborotado" (Ir, 36). Monta temblando el caballo de madera, que se supone ha de llevarlo por los aires: "Parecióle a don Quijote que cualquiera cosa que replicase acerca de su seguridad, sería poner en detrimento su valentía, y así sin más altercar subió sobre Clavileño" (II, 41). Los gatos con cencerros atados a las colas dejan a don Quijote "temeroso" y "pasmado" (II, 46). Cuando toma a doña Rodríguez por una aparición, "temeroso comenzó a decir: conjúrote, fantasma" (II, 48). Al encontrarse con los ahorcados en el bosque vecino a Barcelona, don Quijote se siente "espantado" (II, 60); los bandoleros que lo rodean atribulan tanto al hidalgo, que "tuvo por bien de cruzar las manos, e inclinar la cabeza guardándose para mejor sazón" (II, 60). Cuando la chusma de la galera, en la playa de Barcelona, "con grandísimo ruido dejaron caer la entena de alto a bajo" (II, 63), don Quijote "se estremeció y encogió de hombros, y perdió la color del rostro" (II, 63). Los seiscientos puercos que van acercándose para atropellarlo dejan a don Quijote "alborotado... temeroso" (II, 68). Cuando llegan los jinetes del duque, don Quijote deja ver su miedo en la palabra temer: "podría ser fuese otra cosa de la que tememos" (II, 68), y al verse arrestado "creció el miedo" (II, 68), y cuando le "llaman nombres", "sacaba en limpio... temer mucho mal" (II, 69). Cuando le ponen el sambenito a Sancho "[a] don Quijote... el temor le tenía suspensos los sentidos" (II, 69).

No puede sorprendernos el ver que don Quijote se siente feliz cada vez que encuentra excusas, por muy débiles que sean, para escapar del peligro. No ayuda a Sancho cuando lo mantean, eludiendo su deber por mezquinas razones (I, 17). Cuando Sancho le propone apartarse del camino, don Quijote, "pareciéndole que Sancho tenía razón, sin volverle a replicar le siguió" (I, 19). Después de libertar a 
los galeotes, tan temeroso como Sancho de ser perseguido por la Santa Hermandad, disfraza su temor frente a su escudero: "Eres cobarde, Sancho..., pero porque no digas que soy contumaz... quiero tomar tu consejo; mas... con una condición: que jamás... has de decir a nadie... que yo me retiré y aparté... de miedo" (I, 23). Cuando aparecen los actores con la carreta de Las Cortes de la Muerte, "todo ...visto de improviso, en alguna manera, alborotó a don Quijote" (II, 11). No queriendo realmente atacarlos "púsose a pensar de qué modo los acometería con menos peligro de su persona" (II, 11). Finalmente, cuando Sancho se ve en dificultades con el gracioso de la compañía, don Quijote se retira: “a ti, Sancho, toca, si quieres, tomar la venganza... yo desde aquí te ayudaré con voces y advertimientos saludables" (II, 11). Así repite su cobardísima actitud del manteamiento. Lleno de vergüenza por esta acción, cuando se ven otra vez en camino, suspira don Quijote: “ ¡Si tú, Sancho, me dejaras acometer, como yo quería!" (II, 12).

En una ocasión, cuando apalean a Sancho gentes del pueblo del rebuzno, don Quijote huye: "Volvió las riendas a Rocinante y a todo lo que su galope pudo se salió de entre ellos... temiendo a cada paso no le entrase alguna bala por las espaldas y le saliese al pecho, y a cada punto recogía el aliento por ver si le faltaba" (II, 27); en otras palabras: "don Quijote puso pies en polvorosa y, sin acordarse de Sancho ni del peligro en que le dejaba, se apartó tanto cuanto le pareció que bastaba para estar seguro" (II, 28), actitud tan cobarde y egoísta que rebaja a don Quijote a los ojos de Sancho, el cual, ya con muy poco respeto, comienza a hacerle bromas: "No dejaré de decir que los caballeros andantes huyen" (II, 28). El caso es tan serio que Cortejón, en su comentario, cita la excusa "psicológica" de Pi y Molit, de que don Quijote, después de sus terribles experiencias con arrieros, pastores, galeotes, mozos de mulas, mercaderes y yangüeses, pierde finalmente los ánimos y se vuelve cauto en exceso. Eso es, precisamente, lo que no sólo un santo ni un asceta, pero ni siquiera un héroe o un soldado hubieran hecho, y la excusa, llena de terco orgullo, del propio don Quijote empeora las cosas: "Me he retirado, pero no huído" (rr, 28). Don Quijote siente contento al ver que no tendrá que pelear con el "grande lacayo Tosilos", que anda en tan poderosa cabalgadura. Su primer alivio se lo da la proposición del duque de quitar el hierro a las lanzas: "Don Quijote dijo que su excelencia dispusiese las cosas... como más fuese servido" (II, 56); su alivio final, al negarse Tosilos a pelear: "Oyó esto el valeroso don Quijote y dijo: Pues quedo libre y suelto de mi promesa" (II, 56).

A veces don Quijote traiciona claramente su oculto egoísmo, que en manera alguna está domeñado, al mismo tiempo que alaba su supuesta entrega a la voluntad divina: "Será en balde... persuadirme a que no quiera yo lo que los cielos quieren... y sobre todo mi voluntad desea" (II, 6). Se engaña en esto con tanta astucia, que cuando se niega a tomar a Sansón Carrasco por escudero, rehusa la oferta del bachiller, que, por lo demás, él toma en serio, con las siguientes palabras: "No permita el cielo que por seguir mi gusto desjarrete y quiebre la coluna de las letras" (II, 7). Aquí hasta llega uno a preguntarse si don Quijote no miente a veces con cierta conciencia de que lo hace. ${ }^{8}$ Cide Hamete se siente obligado a debatir este difícil problema: "No

8 Edmund Gayton, en el siglo xvirr, llamó a don Quijote "embustero descarado". Cf. EDwiN 
dijera él una mentira si le asaetearan... No pudo fabricar en tan breve espacio tan gran máquina de disparates [la aventura de la cueva de Montesinos]... Tú, lector, pues eres prudente, juzga lo que te pareciere, ...puesto que se tiene por cierto que al tiempo de su fin y muerte dicen que se retrató della, y dijo que él la había inventado" (Ir, 24). ¿Ascetismo? Antes se pregunta el lector cómo es posible semejante contradicción en un "tan católico y escrupuloso cristiano" (II, 26), cómo se compadece con "la inaudita cristianidad del valeroso don Quijote" (II, 26), según dice irónicamente maese Pedro. La moralidad de don Quijote está mal orientada, no está sometida a perfecta forma: cree con más firmeza en las normas caballerescas que en las cristianas. Si la locura caballeresca de don Quijote fuera inocente, no habría tenido que reconciliarse con Dios, repudiando expresamente sus lecturas y los efectos de éstas: la perturbación provocada por él en su propio espíritu. Ahí está, ciertamente, su culpa, en "la amarga y continua leyenda de los detestables libros de las caballerías", de la cual se siente verdaderamente arrepentido: "Me pesa... que este desengaño ha llegado tan tarde que no me deja tiempo para hacer alguna recompensa, leyendo otros que sean luz del alma" (II, 74). Esto no es beatería, sino la lógica reorientación de un alma caída en el error, de acuerdo con las verdaderas normas cristianas.

¿A qué conclusión se llega, pues, examinando este aspecto del carácter de don Quijote? En teoría, don Quijote procura, con recetas propias, sobrepujar el ascetismo religioso que, para cualquier español del siglo de oro, representa el más alto nivel de moralidad sobre bases espirituales; en la práctica, se hunde, por eso mismo, muy por debajo del nivel que trata de superar. Con palabras de Pascal: Il veut faire l'ange et fait la bête. ¿Qué significa esto para Cervantes? Así como Cervantes reconoce sin duda un mundo objetivo y fenoménico cuya ignorancia paga duramente don Quijote, ${ }^{9}$ así, y con mayor razón, reconoce las normas católicas de moral, que culminan en el ascetismo de los consejos. Estos no pueden tener otra motivación que la cristiana, ni pueden ser olvidados sin padecer catástrofes, como lo experimenta don Quijote, por más que el héroe siga ganándose nuestra voluntad, a pesar de todo, como "compasivo" (II, 52) y "de apacible condición y de agradable trato" (II, 74). Porque Cervantes, "hombre bueno, benévolo, alegre, resignado, paciente, cordial",10 ha aprendido de los verdaderos ascetas de su tiempo a ver cómo las ilusiones hacen que los más de los hombres, aunque sean agradables, inteligentes, sociables, útiles, queden por debajo del ideal: la perfección cristiana. Don Quijote resulta un paradigma de humanistas y alumbrados, los cuales coinciden en un punto de sus tendencias, por lo demás muy dispares: en que tratan de cambiar el ideal cristiano teocéntrico por un conocimiento o emoción antropocéntricos.

Sorprende que una cuestión tan fundamental como la del ascetismo de Cervantes no se haya estudiado ya. Sólo muy recientemente la ha mencionado Américo

B. Knowles, Cervantes and English Literature, en Flores-Benardete, Cervantes across the Centuries, New York, 1948, pág. 270.

9 A. A. Parker, Don Quixote and the relativity of truth, en TDR, xLIv, 1947, I, pág. 36; Américo Castro parece fundamentalmente opuesto a esto; cf. La palabra escrita y el Quijote, en Asomante, Puerto Rico, 1947, mi, pág. 24; cf. en cambio FrIEDRICH SchùrR, loc. cit., págs. 126-130.

10 Roberto F. Giusti, La humanidad de Cervantes, RNC, ixiv, 1947, pág. 7. 
Castro. ${ }^{11}$ Por el presente estudio, apoyado en buen número de pasajes del Quijote y en otros aspectos de su técnica de composición y caracterización de los personajes, me parece que el problema de la actitud de Cervantes ante el ascetismo no es meramente periférico. El resultado se nos confirma si tenemos en cuenta el espíritu general de la época de Cervantes, aunque, como antes he dicho, haría falta analizar también, desde el mismo punto de vista, las otras obras de Cervantes. Desde el solo ángulo de la. conducta de don Quijote, podemos, de acuerdo con Castro, calificar su actitud de vitalista o existencialista, porque reacciona frente a la vida de manera imprevisible, sin principios morales fijos; ${ }^{12}$ pero esta interpretación se desentiende de la crítica moral de Cervantes implícita en las derrotas continuas de don Quijote y en su conversión final. Muy discutible me parece la más reciente interpretación de Farinelli: ver en un don Quijote deliberadamente ilusionista el ideal mismo de Cervantes. Un Cervantes que necesitaba y amaba las ilusiones como escape a las asperezas de la vida, ${ }^{13}$ que de ningún modo estaba dispuesto a sobrellevar y dominar con espíritu ascético.

HELMUT HATZFELD

Catholic University, Washington.

11 En su brillante artículo Incarnation in Don Quixote, en A. Flores y M. Benardete, Cervantes across the centuries, pág. 174, nota 19, Castro habla muy hermosamente de que el tema de la literatura española, y también el del Quijotc, se podría cifrar como la dificultad de vivir, cuando se trata de integrar el cuerpo, alma y mentc; y en nota (19, pág. 174) recuerda el papel angustiador que el hambre tiene en la literatura española. Con esta ocasión Castro observa: "A Cervantes no le atraen el ascetismo ni la pobreza." Y apoya esta observación en un pasaje del Quijote, II, 44, que él explica entre corchetes: "He must have a great deal of godliness [that is to say of the "superman", of the "inhuman"] who can find any satisfaction in being poor." Pcro como el original dice "lia de tener mucho de Dios el que se viniere a contentar con ser pobre", debe entenderse: "el pobre ha de tener mucha gracia de Dios para que se contente con su pobreza'. Cervantes insiste aquí en su tema de la justicia social, de los hidalgos pobres c, implícitamente, de "la estrecheza ordinaria de los soldados" ( $\mathrm{Ir}, 60)$; insiste en que "todas nuestras locuras proceden de tener los estómagos vacíos" (Ir, l) y en que "el pobre está inhabilitado" (r, 50). Esto es, habla de la miseria contraponiéndola a la renunciación. A Cervantes pudo habcrle atraído el ascetismo, pero no la miseria (como en el caso de Léon Bloy en el siglo xIx); y, aunque no le atrajera en la práctica, reconocía la grandeza de la pobreza ascética, como se ve por la frase introductoria, en que el moro no oculta su entusiasmo por el ideal cristiano: "Yo, aunque moro, bien sé... que la santidad consiste en la caridad, humildad... y pobreza; pero con todo eso digo que..." (sigue la frase citada por Américo Castro).

12 Americo Castro, Incarnation in Don Quixote, en Flores y Benardete, loc. cit., págs. 136-178.

13 Arturo Farinelli, Aspects of the spiritual life of Cervantes, SpanCInd, II, 1947, xxir, págs. $29-30$. 